\title{
Article
}

Arq Neuropsiquiatr 2011;69(3):502-508

\section{Headache among medical and psychology students}

\author{
João Eliezer Ferri-de-Barros ${ }^{1}$, Mauricio José de Alencar², \\ Luis Felipe Berchielli ${ }^{3}$, Luis Carlos Castelhano Junior ${ }^{3}$
}

\begin{abstract}
Headaches occur frequently and thus are a key component of sociocentric medical education. Objective: To study headaches among students of medicine and psychology in a single university. Method: This was a questionnaire-based survey of a cohort of students of medicine and psychology. Results: The overall lifetime prevalence of headache was $98 \%$ and over the last year, $91 \%$. Tensional headache accounted for $59 \%$ and migraine $22 \%$ in medicine; and $48.5 \%$ and $32 \%$ respectively in psychology. Forty-five percent reported that headaches had a variable sporadic impact on their productivity. The self-medication rate was $77 \%$. Thirty-six percent reported worsening since admission to the university. Conclusion: The prevalence of headaches was very high. Tension-type headaches predominated in males and migraine in females. Tension-type was more frequent among medical students than among psychology students; migraine was more frequent in psychology (more females) than in medicine. Both kinds of students reported that headaches caused low interference with daily activities. The students reported that their symptoms had worsened since admission to the university.

Key words: headaches, migraine, tension-type headache, medical students, psychology students, sociocentric education.
\end{abstract}

\section{Cefaléia em estudantes de medicina e psicologia}

\section{RESUMO}

Cefaléia é frequente e tema importante para a educação médica sociocêntrica. Objetivo: Estudar cefaléias entre estudantes de medicina e de psicologia. Método: Foi estudo coorte, baseado num questionário respondido pelos estudantes. Resultados: Cefaléia pelo menos uma vez na vida ocorreu em $98 \%$ dos estudantes; no último ano, 91\%.Cefaléia tensional ocorreu em 59\% e enxaqueca em 22\% na Medicina; na Psicologia 48,5\% e $32 \%$, respectivamente. De todos os estudantes, $45 \%$ relataram interferência variável na produtividade. No geral, a taxa de automedicação foi $77 \%$; relataram piora da cefaléia desde o ingresso na universidade $36 \%$. Conclusão: A prevalência de cefaléias foi muito alta. Cefaléia tensional predominou nos homens e enxaqueca nas mulheres. Cefaléia tensional ocorreu mais na Medicina do que na Psicologia; enxaqueca foi mais prevalente em Psicologia (onde havia predomínio do gênero feminino) do que Medicina. Nos dois grupos houve baixa interferência na produtividade; houve piora dos sintomas desde o ingresso na universidade.

\section{Correspondence}

Luis Felipe Berchielli

Alameda dos Jurupis 900 / apto 24 T3 04088-002 São Paulo SP - Brasil

E-mail: luisfelipeberchielli@yahoo.com.br

\section{Support}

This study was financially supported by the State of São Paulo Research Support Foundation (FAPESP) - grant numbers 05/00795-7 and 05/00796-3

Received 5 July 2010

Received in final form 4 March 2011

Accepted 15 March 2011

Palavras-chave: cefaléias, enxaqueca, cefaléia tensional, estudantes de medicina, estudantes de psicologia, educação sociocêntrica.

The programmed content of a medical undergraduate curriculum should be focused on the real needs of the population ${ }^{1}$.
The development of medical professionals needs to take into consideration the nonspecialized important problems and dis- 
eases that prevail in society. This idea is named sociocentric education.

Headaches have a sociocentric dimension, as demonstrated in a previous study ${ }^{2}$. In that study, headaches were the second biggest cause of attendance in emergency services. In a general outpatient clinic, headaches were found to be the third commonest diagnosis and, in a neurology clinic, they were the patients' most frequent complaint ${ }^{3}$.

Headaches are one the most prevalent diagnosis in clinical neurology. Raffaelli and Martins ${ }^{4}$ reported that 93\% of their study population presented some form of headache during their lives. In their cohort, $76 \%$ of females and $57 \%$ of males reported having at least one headache episode per month. Sanvito et al. ${ }^{5}$ identified that the prevalence of diverse types of headaches among medical students at Santa Casa of São Paulo Medical School was $47 \%$ and that the prevalence of migraines was $40 \%$ among the same students. Fifty-four percent of the students who reported headaches were females and $28 \%$ were males, in a sample of 595 students. Costa et al. ${ }^{6}$ showed that $80 \%$ out of 408 medical students at the Federal University of Santa Catarina reported having headaches and that $16 \%$ of the cohort suffered from headaches frequently. In a similar study, Muñiz et al. $^{7}$ found that $95 \%$ of 96 medical students had experienced headaches or migraines in their lifetimes. Headaches were prevalent in $96 \%$ of the females and in $94 \%$ of the male subjects. Migraines were prevalent in 20\% of the subjects: $23 \%$ for female and $16 \%$ for male subjects. Amayo, Jowi and Njeru ${ }^{8}$ applied a specific questionnaire to 711 medical students at the Kenyan Medical School and the Kenyan Medical Training Center in 1996. Six hundred and twenty-five (88\%) of the 711 students had had at least one headache episodes during the six months preceding data gathering. Two hundred and forty subjects (33\%) had migraine according to the International Headache Society criteria, with a 1.3:1 female/ male ratio. Deleu et al. ${ }^{9}$ studied the prevalence and clinical characteristics of headaches among medical students at the Sultan Qaboos University, in Oman. In their study, $96 \%$ of the subjects had presented at least one headache episode during the year preceding data gathering. Rabello ${ }^{10}$ interviewed 407 nurses in his doctoral thesis research. This study reported that the lifelong prevalence of headaches among his research subjects was 97\% (93\% for males and $97 \%$ for females). The same study showed that 216 (54\%) of the research subjects had migraines and that 158 (40\%) had tension-type headaches.

The purpose of this study was to analyze clinical and epidemiological characteristics of headaches among medical and psychology university students at a single institution. To determine the prevalence of head- aches in a cohort of undergraduate students of medicine and psychology at Taubaté University, focusing on two headache subtypes: migraines and tension-type headaches. To compare epidemiological data on headaches among students of medicine and psychology. To evaluate the clinical impact of headaches on the social and academic activities of the research subjects, with analysis on self-medication rates and absenteeism from university classes. To evaluate whether there had been any worsening of the headache since university admission.

\section{METHOD}

After ethics board review and approval of our project and the informed consent statement that we would use (Taubaté University Research Ethics Committee no. 330-03), we recruited students from years 1 to 4 in the Schools of Medicine and Psychology of Taubaté University, Brazil. Out of almost 480 students who were eligible, 344 agreed to take part as research subjects by signing the informed consent statement. Two medical students applied a structured questionnaire to our research subjects, addressing several questions concerning headaches. The subjects gave written responses to the questions in the classroom and the average time taken to complete the questionnaire was 9 minutes. Data analysis was performed.

We used the $2^{\text {nd }}$ edition of the International Classification of Headache Disorders ${ }^{11}$ to make the differential diagnosis between migraine and tension-type headache, according to the responses provided by the research subjects. We did not differentiate between subtypes of primary headaches such as migraine with or without aura, or episodic or chronic tension-type headache. Also, we did not study other forms of primary headaches, such as cluster headache or paroxysmal hemicrania or secondary headaches.

\section{RESULTS}

Three hundred and forty-four students completed the questionnaire (241 were medical students and 103 were psychology students). There were 117 male subjects (34\%) and 227 female subjects (66\%), i.e. a male/female ratio of 1:1.94.

One hundred and six medicine students were males (44\%) and 135 were females (56\%) (male/female ratio $=1: 1.27)$. Eleven psychology students(11\%) were male and $92(89 \%)$ were female (male/female ratio $=1: 8.36$ ). The students' average age was 22.3 years (standard deviation 4.25), ranging from 17 to 48 years of age, and this was similar for male and female subjects. The average age among the psychology students was 24.4 years and it was 21.4 years for the medical students. 
Table 1. Prevalence of different types of headache, according to gender, among medical and psychology students at Taubaté University.

\begin{tabular}{lccc}
\hline & \multicolumn{2}{c}{ No. (\%) of students } & \\
\cline { 2 - 3 } Diagnosis & Male & Female & Total \\
\hline Tension-type headache & $79(67.5 \%)$ & $127(56 \%)$ & $206(59.9 \%)$ \\
Migraine & $22(18.8 \%)$ & $56(24.7 \%)$ & $78(22.6 \%)$ \\
Never had headache & $3(2.6 \%)$ & $1(0.4 \%)$ & $4(1.2 \%)$ \\
No diagnostic & $13(11.1 \%)$ & $43(18.9 \%)$ & $56(16.3 \%)$ \\
Total & $117(100 \%)$ & $227(100 \%)$ & $344(100 \%)$ \\
\hline
\end{tabular}

Table 2. Prevalence of different types of headache, according the course (medicine or psychology), among students at Taubaté University.

\begin{tabular}{lccc}
\hline & \multicolumn{2}{c}{ No. (\%) of students } & \\
\cline { 2 - 3 } Diagnosis & Medicine & Psychology & Total \\
\hline Tension-type headache & $156(64.7 \%)$ & $50(48.5 \%)$ & $206(59.9 \%)$ \\
Migraine & $45(18.7 \%)$ & $33(32.0 \%)$ & $78(22.7 \%)$ \\
Never had headache & $4(1.7 \%)$ & 0.0 & $4(1.2 \%)$ \\
No diagnosis & $36(14.9 \%)$ & $20(19.4 \%)$ & $56(16.3 \%)$ \\
Total & $241(100 \%)$ & $103(100 \%)$ & $344(100 \%)$ \\
\hline
\end{tabular}

\section{Epidemiological data}

The lifetime prevalence of headaches was $98.8 \%$. The last-year prevalence of headaches was $91 \%$. The distribution of headache types according to gender is displayed in Table 1 and Graph 1. The prevalence of different types of headache, according the course (psychology or medicine) is demonstrated in Table 2. The prevalence of migraine or tension-type headache according the course (medicine or psychology) is demonstrated in Table 3 and Graph 2; the difference was significant $(p=0.003)$.

\section{Clinical impact}

Self-medication - The self-medication rate according the course (medicine or Psychology) is displayed in Table 4. The difference in self-medication rates between students of medicine and psychology was not significant $(\mathrm{p}=0.159)$.

Eighty-five percent of the first-year medical students reported self-medication, which was the highest selfmedication rate among our research subjects. In contrast, 79\% of the fourth-year medical students reported self-medication. Eighteen of the second-year students (28\%) said that they only took headache medicines after receiving adequate professional advice. Although the fourth-year medical students had greater knowledge about pharmacology and neurology, the self-medication rate among them was lower (79\%) than among the firstyear medical students (85\%). However, there were no statistically significant differences in self-medication rates among the medical students of the different years.

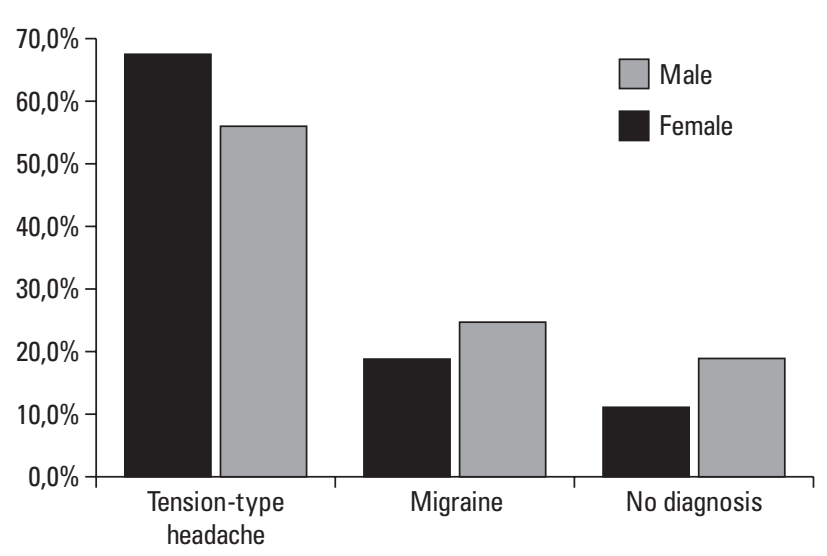

Graph 1. Prevalence of migraine and tension-type headache, according to gender, among medical and psychology students at Taubaté University.

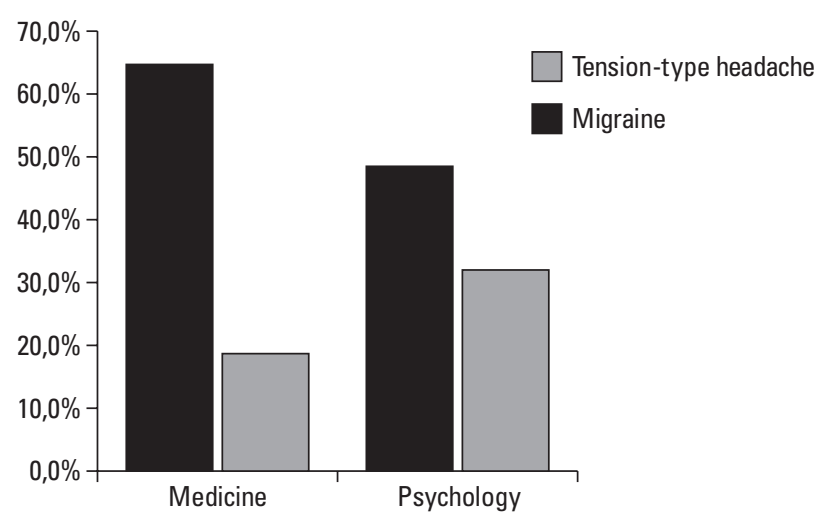

Graph 2. Prevalence of migraine or tension-type headache, according the course (medicine or psychology), among students at Taubaté University. 
Table 3. Prevalence of migraine and tension-type headache, according to the course (medicine or psychology), among students at Taubaté University.

\begin{tabular}{lcccc}
\hline & $\begin{array}{c}\text { Tension-type } \\
\text { headache }\end{array}$ & Migraine & Total & p \\
\hline Medicine & $156(75.7 \%)$ & $45(57.7 \%)$ & $201(70.8 \%)$ & 0.003 \\
Psychology & $50(24.3 \%)$ & $33(42.3 \%)$ & $83(29.2 \%)$ & 0.003 \\
Total & $206(100 \%)$ & $78(100 \%)$ & $284(100 \%)$ & \\
\hline
\end{tabular}

Table 4. Self-medication rate according the course (medicine or psychology), among students at Taubaté University.

\begin{tabular}{lccc}
\hline & \multicolumn{3}{c}{ No. (\%) of students } \\
\cline { 2 - 4 } Self- medication & Medicine & Psychology & Total \\
\hline Yes & $189(79.7 \%)$ & $75(72.8 \%)$ & $264(77.6 \%)$ \\
No & $48(20.3 \%)$ & $28(27.2 \%)$ & $76(22.4 \%)$ \\
Total & $237(100 \%)$ & $103(100 \%)$ & $340(100 \%)$ \\
\hline
\end{tabular}

$\mathrm{p}=0.159$

Table 5. Percentage of worsening headache symptoms, since university admission, according the course, Medicine or Psychology, among students in Taubaté University.

\begin{tabular}{lccc}
\hline & \multicolumn{3}{c}{ No. (\%) of students } \\
\cline { 2 - 4 } Headache worsening & Medicine & Psychology & Total \\
\hline Yes & $85(35.9 \%)$ & $38(36.9 \%)$ & $123(36.2 \%)$ \\
No & $152(64.1 \%)$ & $65(63.1 \%)$ & $217(63.8 \%)$ \\
Total & $237(100 \%)$ & $103(100 \%)$ & $340(100 \%)$ \\
\hline $\mathrm{p}=0.86$ & &
\end{tabular}

Eighty-four percent of the first-year and $67 \%$ of the second-year psychology students reported self-medication. There was no statistically significant difference in self-medication rates among the psychology students of the different years.

Interference with social and academic activities - Thirty-nine percent of our research subjects reported that headaches rarely interfered with their social and academic activities. Thirty-six percent of the subjects reported that "sometimes" they felt that headaches interfered with their activities, and only three students (0.9\%) believed that headaches constantly interfered with their social and academic activities. The remaining $24 \%$ of the students reported that headaches never interfered with their social and academic activities. Psychology and medical students were clearly different in terms of the impact of headaches on their activities. Forty-three percent of the medical students reported that headaches only possibly interfered with their activities, whereas $44 \%$ of the psychology students reported that headaches regularly interfered with their activities.

Productivity - Forty-five percent of the students (46\% of medical students and $43 \%$ of psychology stu- dents, $\mathrm{p}>0.05$ ) reported that headaches only sporadically interfered with their productivity. Only two medical students reported that headaches always interfered with their productivity, and two psychology students left this question unanswered.

Absenteeism - More than fifty percent of the research subjects reported never missing university classes due to headaches. Only four students (three medical students and one psychology student) reported that they frequently missed classes, and no student reported having always missed classes because of headaches. Two psychology students and one medical student left this question unanswered.

Headache worsening since university admission - Table 5 shows the data relating to worsening of headaches since university admission for medical and psychology students.

\section{DISCUSSION}

Our literature review and our data suggest that headaches are highly prevalent in the general population and among university students. Studies reporting the prevalence of headache in the general population have shown 
lifetime prevalence rates of $71 \%$ to $96 \%^{4,12-14}$ and last-year headache prevalence rates of $64 \%$ to $77 \% \%^{15-17}$.

Ferri-de-Barros and Nitrini showed that headaches were the third commonest diagnosis in a sample at general outpatient clinics and the most frequent diagnosis in a sample at neurology outpatient clinics ${ }^{3}$. The high prevalence of headaches in the general population has several implications for planning the delivery of clinical care and for medical education. Our research group has focused on planning medical education in clinical neurology based on the concept of sociocentric education. Studying headaches constitutes an important part of sociocentric education in clinical neurology, and this has been suggested in a previous study ${ }^{2}$. In that study, headaches were the second biggest cause of visits to emergency services in São Paulo.

Studying headaches among university students is important, based on the premise that this population may be more subject to headaches than the general population, for reasons relating to academic life that are known to trigger headaches ${ }^{5,10,12}$, such as emotional stress and poor sleeping and feeding habits (including abusive use of caffeine and other psychoactive substances). Medical students and psychology students are similarly exposed to risk factors that trigger headaches and, in our study, we recruited students from the Schools of Medicine and Psychology for convenience sampling.

Ho and $\mathrm{Ong}^{18}$ interviewed university students at the National University of Singapore. They reported that the lifetime headache prevalence was $98 \%$. Martinez and Sanchez ${ }^{19}$ reported that the last-year headache prevalence was $92 \%$ among university students in Madrid. They reported that the lifetime headache prevalence among women was close to $100 \%$ and $97 \%$ among men, and that this difference was statistically insignificant; however, the last-year headache prevalence was significantly higher among women (93\%) than among men $(86 \%)(\mathrm{p}<0.05)$.

We found only a few studies concerning headaches among medical or psychology students. Deleu et al. ${ }^{9}$ reported that the lifetime headache prevalence was $98 \%$ in medical students at Sultan Qaboos University, in Oman, which coincides with our data. The last-year headache prevalence in their study was $97 \%$, which is slightly higher than the finding of $90 \%$ in our cohort of medical students who reported to have headache during the year preceding data gathering. Blau ${ }^{20}$ reported that only $2 \%$ of his subjects (medical and dental students) had never had any headaches during their lives. In a study conducted by Monteiro et al. ${ }^{21}$ in Portugal, medical students reported lifetime and last-year headache prevalences of $97 \%$ and $92 \%$ respectively. Two studies by Muñiz et al. ${ }^{7,22}$ in Spain, detected a lifetime headache prevalence of $96 \%$ and a last-year headache prevalence of $92 \% ; 100 \%$ of the psychology students had presented a headache during their lifetimes. The last-year headache prevalence was $93 \%$ in the same study, which was similar to what was reported by Martinez and Sanchez ${ }^{19}$.

Our findings of higher prevalence of headaches among women is consistent with several other studies $^{5,6-10,21,22}$. In our study, the overall lifetime headache prevalence among men (97\%) and women (100\%) and the last-year prevalence among men (86\%) and women (93\%) were comparable with previous reports by Deleu et al. ${ }^{9}$ and Costa et al. ${ }^{6}$. The male/female ratio was 1:1.94. Our finding of higher prevalence of migraine among psychology students may be explained by the fact that there were more female subjects in the psychology school, and that migraine-type headaches affect more females than males ${ }^{10}$.

Self-medication and clinical impact - The overall self-medication rate among our subjects was 78\%: $80 \%$ for medical students and $73 \%$ for psychology students, and the difference in these rates was not significant. Costa et al. ${ }^{6}$ found that $84 \%$ of their research subjects (medical students) reported self-medication and that $34 \%$ of their subjects reported seeking medical care for their headaches. Deleu et al. ${ }^{9}$ reported a self-medication rate of $80 \%$ among medical students and that only $23 \%$ of their research subjects reported seeking medical assistance for their headaches. In Blau's study ${ }^{20}$, the number of headache sufferers that reported seeking medical care was $8 \%$. Amay et al. ${ }^{8}$ found a $56 \%$ self-medication rate among their subjects, and half of their subjects reported seeking medical assistance during their headache crisis. In another study by Deleu et al..$^{9}$ which was conducted in a farming community in Oman, the self-medication rate was $40 \%$.

The variable self-medication rate described in the literature may be due to sociocultural differences among the diverse research subjects in different studies, while the relatively high rate of self-medication reported by medical and psychology students is probably related to the students' level of education, knowledge of pharmacology and ease of access to painkillers. Fifty-two percent of our subjects reported never missing classes due to headaches. This may be a result from effective selfmedication that relieved the symptoms, mild intensity of symptoms, or strong motivation among students to attend classes; or, most likely, a combination of all factors. We hypothesize that our research subjects were highly motivated to attend university classes because current teaching philosophy in Brazil strongly values classroom interaction between professors and students, and because students are generally conscious of and keen to enhance their learning experiences. Moreover, students 
are subject to intense academic responsibilities and evaluations and missing classes may have a negative impact on the student's performance. Our hypothesis is based on the fact that out of the twenty-nine subjects in our study who reported suffering from incapacitating headaches, six had never missed classes due to headaches, ten occasionally did, ten regularly did and only three frequently missed classes due to headaches. Further research with multivariate analysis or qualitative methodology would be required to investigate the reasons for absenteeism.

The fact that more psychology students reported that headaches interfered with their activities, as compared with the medical students in our study, may be due to the fact that they were predominantly female. Hence, they would suffer migraine more frequently, and we hypothesize that they would have headaches of greater intensity. In a study conducted by Costa et al. ${ }^{6}, 34 \%$ of the research subjects (medical students) reported having severe limitations to their daily routine as a result of headaches, and $3 \%$ reported having incapacitating headaches that impeded them from performing any activities during their headache crises.

The finding of worsening headache since admission to the university (35.9\% for medicine and 36.9\% for psychology) may due to the natural stress within the course objectives. This, of course, is not the only possible understanding, and therefore the data need further investigation.

Our findings have implications for clinical care and university education. In medical education, the academic community and the national medical council (CFM) have constantly expressed concerns regarding the quality of medical education in Brazil. The implementation of a nationwide standard medical curriculum (core curriculum) and standard evaluations on medical undergraduates are two measures that would likely improve the quality of medical education in Brazil. This is based on empirical experiences from other countries where this has been effectively implemented and based on the fact that such measures (standardizing the curriculum and evaluations) would allow for greater accountability in medical education. Developing a core curriculum that is widely accepted is one of the challenges in medical education. We argue that the curriculum for medical undergraduate courses must take into account the needs of the population ${ }^{1}$, and this is a well-known concept named sociocentric education. The present study shows that there is a need to emphasize the study of headaches in medical education because headaches are highly prevalent among the general population, and also among university students. We also perceive that there is a strong need to restore the professor/student relationship in medical education and that implementation of elective activities complementing classroom education is likely to stimulate self-learning ${ }^{1}$, which is a lifelong skill that physicians must possess for continuing medical education.

The limitations of our study relate mostly to resource constraints. For example, the limited amount of time available for students to answer questions in the classroom limited the number of questions that we were able to ask. This, in turn, limited our ability to accurately differentiate between headache types, and we may have overestimated the prevalences of migraines and tension-type headaches. However, other studies that included clinical questions and physical examinations have shown that the prevalence of secondary headaches is low, and thus our methods and results have acceptable face value. With additional resources, it would be interesting to apply focus group interviews with diverse groups of students to further study the issues of self-medication and absenteeism, since answers to questionnaires may vary depending on whether questions are answered individually or in groups.

In conclusion, the lifetime prevalence of headaches was $98.8 \%$; the last-year prevalence was $91 \%$. The prevalence of tension-type headache was $67.5 \%$ in males and $56 \%$ in females. The prevalence of migraine was $18.8 \%$ in males and $24.7 \%$ in females. Among the medical students, the prevalence of tension-type headache was 64.7\% and migraine, 18.7\% (1.7\% had never had headaches, and there was no diagnosis in 14.9\%). Among the psychology students, the prevalence of tension-type headache was $48.5 \%$ and migraine, $32 \%$ (no diagnosis in 19.4\%). The students reported that headache symptoms had a low impact on their daily social or academic activities (39\% reported that headaches rarely interfered with their social and academic activities and 36\% reported that they "sometimes" did). They also reported that there was a low rate of absenteeism in their classes and a high rate of self-medication (77.6\%). The students reported that their headache since admission to the university (35.9\% for medicine and 36.9\% for psychology).

ACKNOWLEDGMENTS - Our thanks to Fábio Ferri-de-Barros, MD , who helped us correct the English writing.

\section{REFERENCES}

1. Marcondes E, Montes GS, Bianco AC. A proposta do curriculo nuclear. In: Marcondes E, Gonsalves EL (Eds). Educação medica. São Paulo, Sarvier, 1998:174-182.

2. Ferri-de-Barros JE, Veiga JCE, Priante AVM, et al. Transtornos neurológicos mais frequentes: contribuição para a definição de temas do conteúdo programático do curso de Neurologia, para a graduação médica. Arq Neuropsiquiatr 2000;58:128-135.

3. Ferri-de-Barros JE, Nitrini R. Que pacientes atende um neurologista? Alicerce de um currículo em Neurologia. Arq Neuropsiquiatr 1996;54: 637-644

4. Raffaelli Jr E, Martins OJ. Dor de Cabeça. O que se diz... O que se sabe... 4a ed. São Paulo, Lemos Editorial, 2001:25. 
5. Sanvito WL, Monzillo PH, Peres MFP, et al. The epidemiology of migraine in medical students. Headache 1996:36:316-319.

6. Costa MZG, Soares CB, Heinisch LMM, Heinisch RH. Frequency of headache in the medical students of Santa Catarina's Federal University. Headache 2000;40:740-744.

7. Muñiz R, Montiel I, Asensio M, Martin R, Matias-Guiu J. La prevalência de la migraña en una poblácion de estudiantes universitários. Rev Neurol 1995 23:866-869.

8. Amayo EO, Jowi JO, Njeru EK. Migraine headaches in a group of medical students at the Kenyatta National Hospital, Nairobi. East 4fr Med J 1996; 73:594- 597.

9. Deleu D, Khan MK, Humaidan H, AL Mantheri Z, Hashami S. Prevalence and clinical characteristics of headache in medical students in Oman. Headache 2001;41:798-804.

10. Rabello GD. Estudo transversal em uma população hospitalar: fatores constitucionais e ambientais relacionados à enxaqueca. Tese de doutorado. Faculdade de Medicina da Universidade de São Paulo. São Paulo, 2000: 33-51.

11. Headache Classification Subcommittee of the International Headache Society. The International Classification of Headache Disorders. $2 \mathrm{n}^{\mathrm{d}}$ Edition. Cephalalgia 2004;24 (Suppl 1):S16-S54.

12. Feldman AS. Enxaqueca: alívio para a sofrimento. São Paulo, Siciliano, 1994.
13. Ho KH, Ong BK A. Community-based study of headache diagnosis and prevalence in Singapore. Cephalalgia 2003;23:6-13.

14. Rasmussen BK, Jensen R, Schroll M, Olesen J. Epidemiology of headache in a general population: a prevalence study. J Clin Epidemiol 1991;44:1147-1157.

15. Gobel H, Petersen-Braun M, Soyka D. The epidemiology of headache in Germany: a nationwide survey of a representative sample on the basis of the headache Classification of International Headache Society. Cephalalgia 1994;14:97-106.

16. Alders EE, Hentzen A, Tan CT. A community-based prevalence study on headache in Malaysia. Headache 1996;36:379-384.

17. Nikiforow R. Headache in a random sample of 200 persons: a clinical study of a population in northern Finland. Cephalalgia 1981;1:99-107.

18. Ho KH, Ong BK. Headache and self-assessed depression scores in Singapore University undergraduates. Headache 1997;37:26-30.

19. Martinez SF, Sanchez HA. Prevalencia de cefaleas en una poblácion universitária. Rev Sanid Hig Publica (Madr) 1992;66:313-317.

20. Blau JN. Common headaches: type, duration, frequency and implications. Headache 1990;30:701-704

21. Monteiro JM, Matos E, Calheiros JM. Headaches in medical school students. Neuroepidemiology 1994;13:103-107.

22. Muniz R, Macia C, Montiel l, et al. Prevalence of migraine in the medical student population as determined by means of the "Alcoi 1992" questionnaire. Rev Neurol 1995;23:870-873. 